\title{
Investigate the Effects of Flipped Learning on Understanding of Mathematics for Secondary Students
}

\author{
Dunia Zeineddine \\ Long Beach Unified School District, California
}

\begin{abstract}
The purpose of this study was to examine the effect of the flipped classroom on learning outcomes and increased student participation in problem solving with reasoning in the high school precalculus classroom. Twenty three students in a precalculus class were given a traditional lecture and assigned homework to be completed away from class; twenty students were taught using flipped learning where they read and viewed lecture videos outside of class with focus on problem-solving in class. Three worksheets were collected to measure student participation in problem-solving with reasoning. The results were analyzed quantitatively. Results of this study showed that participation in problem solving increased for students who did not regularly complete homework as a result of implementing the flip.
\end{abstract}

Keywords: Flipped classroom, traditional classroom, problem solving, cognition

California Schools are implementing the Common Core State Standards and students are expected to achieve deep understanding of mathematical concepts and consequently perform well on the Smarter Balanced test (Smarter Balanced, 2012).

Although the traditional teaching methods have been successful in helping students achieve mathematical skills with less than adequate levels of understanding on average, there is a need to try another teaching method in an attempt to increase the deep understanding of concepts and applying them to problem solving (Freeman, Eddy, McDonough, Smith, Okoroafor, Jordt, \& Wenderoth, 2014). The traditional teacher-centered lectures are ineffective in teaching students with understanding. The problem is not that lecturing is bad for students, but that there is not enough time for both lecture and in-class problem solving group sessions (Schwerdt \& Wupperman, 2010). The lack of deep understanding is attributed mostly to lack of time invested in problem solving since the teacher is usually rushed to complete a vast curriculum within an inadequate amount of time. This is especially true for higher level classes like precalculus where students are expected to achieve fluency in complex algebraic skills with a variety of solution strategies in a variety of topics. Excluding between-teacher variations which could influence the way 
any teaching style is implemented, and therefore produce different results, when students are given more time to work on complex mathematical problems with peer and teacher support, students will benefit. If we want teachers, administrators, and school districts to buy into the flipped model, more research is needed to prove the effectiveness of the flipped model in creating an interactive learning environment that promotes student understanding in the secondary school.

This study is an attempt at finding a better way to teach with understanding through the Flipped Classroom model. Students are introduced to the lecture materials through a combination of online notes and a prerecorded lecture by their teacher or other sources, they complete an accompanying assignment to encourage students to view the videos, and then students will have a cognitively challenging, predesigned peer-group activity to apply the lesson in class with teacher guidance.

\section{The Purpose of Study and Research Questions}

The purpose of this research study was to investigate the benefits of the Flipped Learning model in increasing student test scores and student participation in solving application problems with explanation and reasoning in the high school precalculus classroom. This research study investigated the answer to two main questions:

(1) Will the flipped classroom model result in higher test scores in comparison to the traditional classroom model in the high school precalculus class?

(2) Will students participate in application problem solving and explain their work with mathematical reasoning to a greater extent with the flipped classroom compared to the traditional teacher-centered classroom?

\section{Theoretical Framework}

Two high school Chemistry teachers, Johnathan Bergmann and Aaron Sams started recording videos as lectures in 2007 to free more class time to work on meaningful and engaging assignments. It later came to be called the Flipped Learning or Flipped Classroom (Noonoo, 2012). The definition of the flipped classroom used in the context of this literature review will include any form of the flip model as long as the main idea is: students will be exposed to the lecture entirely or partially outside of the classroom using video lectures or a combination of video and reading lectures, then they will use class time to work on meaningful challenging problems in a group setting with teacher guidance. It could be completely student driven with teacher as a facilitator, or the teacher may interject mini lectures as needed (Honeycutt, 2014.) However, there seems to be a consensus on the lack of research to prove the efficacy of the flipped classroom model. The research conducted in higher learning institutions and research that requires the purchase of a 
particular resource is beyond the scope of this literature review. Higher education research does not necessarily apply to younger students in the secondary schools who lack the maturity and experience their college counterparts have. And, since this teaching model requires a large investment of time and money by teachers and school districts, further research is needed to support the theory of flipped classrooms as a way to promote higher cognition and student engagement.

\section{History of Flipped Learning}

According to the definition presented by the Flipped Learning Network (founded by Sams \& Bergmann, 2012):

Flipped Learning is defined as a "pedagogical approach in which direct instruction moves from the group learning space to the individual learning space, and the resulting group space is transformed into a dynamic, interactive learning environment where the educator guides students as they apply concepts and engage creatively in the subject matter (Flipped Learning Network, 2014). By moving from a flipped class to actively engaging in Flipped Learning, teachers are able to implement new or various methodologies into their classrooms. It frees up class time, allowing for more individual and small group instruction." (Yarbro, Arfstrom, McKnight, \& McKnight, 2014, p. 5)

Bishop and Verleger (2013) stated in a paper they presented at a conference in Daytona Beach, Florida, a comparison between two models. The first is merely a description of reordering the events of what takes place in a traditional classroom. It offered video lectures away from the classroom, and a combination of practice exercise and problem solving in class. The second offered Video Lectures with closed-ended quizzes and practice exercises away from class, and group-based plus open-ended problem solving in class. The latter example seems to be more like the Flipped Learning Network's definition. Bishop and Verleger (2013) agreed also that the second model is what educators call the flipped classroom citing student-centered learning theories based on the works of Piaget(1967) and Vygotsky(1978) (as cited in Bishop \& Verleger, 2013).

But flipped learning started earlier at the university level. The Harvard University Physics professor Mazor started a version of this model in the early 1990s (as cited in Moore, Gillett, \& Steele, 2014). More recently, when Salman Khan (an MIT graduate) started the Khan Academy producing instructional videos on You Tube in 2006 and others followed in his footsteps, it made using the flipped classroom more possible for other high school teachers. 


\section{Technology and Equity: a Limitation}

Equal access for all students to computers (or tablets or smart phones) and internet is a major concern we as educators are faced with when contemplating the use of the flipped classroom. As one survey conducted by the National Education Association in collaboration with the American Federation of Teachers (2008) reveals that teachers and students in public schools have some access to internet and computers, but not enough access to use them as effective learning and teaching tools. Furthermore, educators are concerned about the disparity in the levels of accessibility for students in different community types or levels (National Education Association, 2008). A teacher has to make sure students have equal access to the technology needed for the implementation of the flipped model. The new trend in education is to supply students with tablets to make the playing field equitable for all students. But, this is not an immediate solution.

\section{Cognition and the Flipped Classroom Improve Student Understanding}

Another component of the effectiveness of technology away from the classroom as a learning tool is what happens in the classroom and how learning takes place. Lave and Wagner (1990, 1991) described situated cognition as the learning that happens in context and culture. Therefore, it is important to know how learning takes place and not only where it happens (as cited in Szymanski \& Morrell, 2009). When the learner (student) develops skills in authentic activities, the goal is to extend this acquired knowledge for future problem solving (Szymanski \& Morrell, 2009). The student will learn and retain the learning more readily in the classroom with the support of peers and the teacher. This is another compelling reason to devote more class time for problem solving rather than pure lecture. To further support this theory, four benefits of situated cognition were discussed by Collins (as cited in Brill, 2001) as a basis for student learning. The first is students learn about the application of knowledge. The second is students are provided a dynamic social environment to encourage invention and creativity in problem-solving. The third is students are more likely to recognize and find from teacher and peers the implications of what they learn. And the fourth is that students are learning with teacher and peer support to insure immediate feedback. This leads to learning the appropriate and correct methods for solving problems. The social and diverse context promotes lasting transferable knowledge that can be applied in future situations. The flipped classroom model promotes student-centered learning and is one of the applications based in part on situated cognition; which leads us to the next section.

\section{Benefits of Active Learning in Problem Solving}

Freeman, Eddy, McDonough, Smith, Okoroafor, Jordt, and Wenderoth (2014), authors of Active Learning Increases Student Performance in Science, Engineering, and Mathematics claimed that this study was the largest to date 
on undergraduate STEM education. The study is an analysis of the benefits of active learning over traditional learning in the STEM education for undergraduate students. The authors of this article conducted a survey and as a result arrived at this definition of active learning: "Active learning engages students in the process of learning through activities and/or discussion in class, as opposed to passively listening to an expert. It emphasizes higherorder thinking and often involves group work." And they used this definition of traditional lecture: "...continuous exposition by the teacher" (Freeman, Eddy, McDonough, Smith, Okoroafor, Jordt, \& Wenderoth (2014, p.841314).

\section{Method}

\section{Site}

The school site is a High School located in an inner city in southern California. It is one of the 10 largest urban schools in the country, well known for its athletics and academics. The school implements the Smaller Learning Communities system to promote academic achievement and equity for such a large high school. Students are placed into a Smaller Learning Community which is managed by one counselor. Students within the smaller community usually have the same teachers. The exception is electives and mathematics classes which include students from different Smaller Learning Communities. The most recent statistics for school enrollment by grade level (2013-2014) shows a total enrollment of 4497 students for grade levels 9-12 with about $24 \%$ African American, $20 \%$ Asian, 35\% Latino, 10\% white, and $11 \%$ of other ethnicities. Also, about 59\% are socioeconomically disadvantaged, $13 \%$ are English learners, and about $9 \%$ are students with disabilities.

\section{Subjects}

Participants in this research study were two $11^{\text {th }}$ grade precalculus classes of one teacher. Students were of mixed ethnic and socio-economic backgrounds reflecting the demographics of the school. They were designated as honors level with mixed levels of mathematical background. Students did not have similar past experiences in learning mathematics as they had different teachers in previous grades, and in many cases came from different middle or high schools. One class consisted of 14 girls and 9 boys, and the other class consisted of 11 girls and 9 boys. Most students were involved in extra-curricular activities which took them away from the classroom occasionally. This affects the classroom experiences of students who miss the problem-solving group sessions since the activities could not be recreated to make up for missed work. 


\section{Procedure}

The first unit taught to both classes for the duration of 3 weeks was on sequences and series, the Binomial Theorem, counting, and probability. One precalculus class (group 1) was taught the traditional way of lecture, examples, guided practice, and homework with some group work. Students in the other class (group 2) were taught the same unit implementing the Flipped Learning method for the same duration. Students of both groups 1 and 2 were given the same pretest composed of 20 questions (chosen from the precalculus text book test bank used at the school) before the unit was taught. The traditional, teacher centered approach for group1 was a lecture with examples, a guided practice, and then homework was assigned. The next day students had a limited portion of class time to ask questions, teacher answered the questions, retaught where necessary, and then the process was repeated for the next part of the unit. As teacher lectured, students were asked questions to connect to prior learning, teacher checked for understanding, and students practiced with examples. Students in the second group were given a short 5-10 minute lecture to introduce a section of the unit and they were asked to take notes on the new concepts using online resources and a note-taking guide as homework. Then they were asked to attempt the corresponding homework assignment. The next day, teacher checked for understanding of key concepts using questions and homework problems for a few minutes. Teacher also provided students with any needed clarification on the lesson in the form of a whole group discussion. They checked and corrected their homework with help from peers and teacher as needed. When the teacher was satisfied that students understood the basic concepts, they were asked to work in small groups on carefully selected complex application problems. Then they shared results as a class with teacher guidance to insure accuracy of responses and solutions. Students of both groups (1) and (2) were given a short quiz after each section which they corrected in class for immediate feedback. Students in the second group consistently did more group work and problem solving sessions than group one.

Another unit on conic sections was taught using a traditional teacher centered model for group (1) and the flipped learning method for group (2). A similar instructional process was implemented as with the previous unit. This unit consisted of four sections taught over a period of three weeks.

Also for this unit, they were given 3 MSAR (model-strategy-application with reasoning) work sheets ( $\mathrm{An} \& \mathrm{Wu}, 2014$ ) where they independently had to model, explain, solve, and justify their work with mathematical reasoning. One worksheet was given after each of the first three sections. Students had a few minutes to ask questions on the MSAR sheets before turning them in.

\section{Instruments and Data Collection}

At the conclusion of the first unit, both study groups were given the same 20-question pretest which was administered prior to teaching this unit as 
a post test. It consisted of problems chosen from the test bank of the text book (Larson, Hostetler, \& Edwards, 2015) used in part for teaching the class. The test given for the second unit consisted of a total of 10 problems in the form of matching, True/False, multiple-choice, short response, extended response, and a performance task. The first 9 questions were based on problems from the same test bank mentioned above, but were slightly modified by the teacher. Another part of the same test was given on another day as a multi-step "performance task" style problem created by the teacher, based loosely on a problem from the test bank. Students were given enough time to complete this problem as needed.

The extent of student participation in problem solving was measured quantitatively using problems given in MSAR format (An \& Wu, 2014). Three problems in the form of MSAR worksheets were assigned right after the respective section, then collected and graded only for participation and showing work with reasoning, and not for accuracy. One MSAR was on circles, the second one was on parabolas, and the third one was on Ellipses (see Appendix A.)

A rubric by Wu and An (2016) was used to score and code the MSAR work sheets (see Appendix A.) The scores of the worksheets were analyzed for Modeling, Strategy, and Reasoning, omitting the Application part for time constraints.

\section{Data Analysis}

Independent $\mathrm{T}$-Tests were used to measure the difference in performance between the traditionally taught group and the flipped learning group.

In order to minimize the threat to validity, the test scores were analyzed on improvement of the posttest scores over the pretest scores. The pretest/ posttest results were compared using an independent t-test to measure the difference in test scores between group (1) and group (2).

The test for unit 2 was analyzed using descriptive statistics and an independent t-test. The two parts of the test were analyzed separately The results show the varying degrees of achievement among the two groups of students and the impact the Flipped Classroom model has made on student learning as opposed to traditional teaching.

\section{Findings}

The following are tables of the SPSS analysis of data collected on the two tests and three MSAR worksheets. Keeping in mind that group (1) was mathematically stronger than group (2) since more students from group (1) came from accelerated Algebra 2 while more students in group (2) came from the regular Intermediate Algebra class which was not designated as an honors class. The other reason group1 students are stronger is they generally do 
homework more consistently. The Flipped Classroom model was a natural consequence for the group (2) students since they needed to work in class with peer and teacher support they were not successfully completing assigned homework.

Table 1 of the descriptive group statistics shows that class 1 of 23 students had a mean pretest score of $M=26.96, S D=15.28$ and class 2 of 20 students had a mean score of $M=24.25, S D=13.01$. The posttest score of class 1 of 22 students (due to absence) had a mean score of $M=75.36, S D=15.14$ and class 2 of 19 students (one absence) had a mean test score of $M=81.16$, $S D=11.04$. Ch 9 test for class 1 had a mean test score $M=69.46, S D=16.53$, class 2 with a mean test score $M=76.81, S D=12.25$. Ch 9 performance task mean score of class one (23 students) was $M=10.04, S D=3.59$ and the mean score of class 2(20 students) was $M=13.40, S D=3.89$.

Table 1

Group Statistics for the Pretest and Posttest for Two Classes

\begin{tabular}{lcccc}
\hline \multicolumn{4}{c}{ Group Statistics } \\
& Group\# & $\mathrm{N}$ & Mean & SD \\
\hline pretest & 1 Class 1 & 23 & 26.96 & 15.281 \\
& 2 Class 2 & 20 & 24.25 & 13.006 \\
post test & 1 Class 1 & 22 & 75.36 & 15.136 \\
& 2 Class 2 & 19 & 81.16 & 11.037 \\
ch 9 total percent & 1 Class 1 & 23 & 69.45 & 16.530 \\
\multirow{3}{*}{ ch9 perf } & 2 Class 2 & 20 & 76.81 & 12.250 \\
& 1 Class 1 & 23 & 10.04 & 3.586 \\
& 2 Class 2 & 20 & 13.40 & 3.885 \\
\hline
\end{tabular}

Notes: pretest refers to the test on sequences and series; posttest is the same test given after the conclusion of the unit. Percent ch 9 refers to the test on conics consisting of 9 questions graded from 60 points changed into a percentage score. Ch 9 perf refers to the performance task graded from 20 points. Class 1 and class2 refer to group1 and group2.

Table 2 shows the results of the independent sample t-test analysis. Table 2 shows there is no significant difference in mean scores for the pretest between two groups $(t(41)=.62, p=.54)$; also for the post-test there is no significance in mean scores between two groups $(t(39)=1.38, p=.175)$; there is no significant difference in mean scores for the chapter 9 test scores between two groups $(t(41)=1.64, p=.109)$; For the performance task, there is significant difference in the mean between two groups $(t(41)=2.95, p=.005)$ 
Table 2

\begin{tabular}{|c|c|c|c|c|c|c|}
\hline & & \multicolumn{2}{|c|}{ Levene's Test } & \multicolumn{3}{|c|}{ t-test for Equality of Means } \\
\hline & & $\mathrm{F}$ & Sig. & $\mathrm{t}$ & df & Sig. \\
\hline pretest & $\begin{array}{l}\text { Equal variances } \\
\text { assumed }\end{array}$ & .610 & .439 & .620 & 41 & .539 \\
\hline posttest & $\begin{array}{l}\text { Equal variances } \\
\text { assumed }\end{array}$ & 1.423 & .240 & -1.38 & 39 & .175 \\
\hline $\begin{array}{l}\text { percent ch } 9 \\
\text { total percent }\end{array}$ & $\begin{array}{l}\text { Equal variances } \\
\text { assumed }\end{array}$ & .918 & .344 & -1.63 & 41 & .109 \\
\hline ch9perf & $\begin{array}{l}\text { Equal variances } \\
\text { assumed }\end{array}$ & .099 & .754 & -2.94 & 41 & .005 \\
\hline
\end{tabular}

Table 3 displays the descriptive statistics of the modeling part of the 3 MSAR worksheets. Modeling refers to the visual representation of the problem to be solved. The mean scores of class 1 of 21 students and class 2 of 18 students(not all students turned in the worksheets) for the first 2

worksheets show very small difference at $M=3.86, S D=.36$ and $M=3.94$, $S D=.24$ for the first worksheet, and $M=3.52, S D=.60$ and $M=3.67, S D=.46$ for the second worksheet. The mean scores of the last worksheet show more of a difference between class $1(M=3.67, S D=.48)$ and class $2(M=3.94, S D=.24$. $)$

Table 3

Descriptive Statistics for MSAR 1, 2, and 3 for "Modeling"

\begin{tabular}{llrrr}
\hline \multicolumn{5}{c}{ Group Statistics } \\
\hline & Group\# & N & Mean & Std. Deviation \\
\hline MSAR1modeling & 1 Class 1 & 21 & 3.86 & .359 \\
& 2 Class 2 & 18 & 3.94 & .236 \\
MSAR2modeling & 1 Class 1 & 21 & 3.52 & .602 \\
& 2 Class 2 & 18 & 3.67 & .485 \\
MSAR3modeling & 1 Class 1 & 21 & 3.67 & .483 \\
& 2 Class 2 & 18 & 3.94 & .236 \\
\hline
\end{tabular}

Notes: Table 3 shows the results of the modeling part only of the MSAR worksheet.

Table 4 displays the results of the t-test. This is comparing the worksheet scores of the modeling part of all 3 worksheets for the two groups being studied, class 1 (control group) and class 2 (flipped class.) Worksheet 1 was on circles, the first section of the conics unit. Table 4 shows there is no significant difference in mean scores between two groups $(t(37)=.88, p=.38$ ), 
Worksheet 2 was on parabolas, also the first section of the conics unit. Table 4 shows there is no significant difference in mean scores between two groups $(t(37)=.81, p=.43)$,

Worksheet 3 was on ellipses, the second section of the conics unit. Table 4 shows there is significant difference in mean scores between two groups $(t(37)=29.4, p=.027)$.

Table 4

Independent samples test for MSAR 1, 2, and 3 for "modeling"

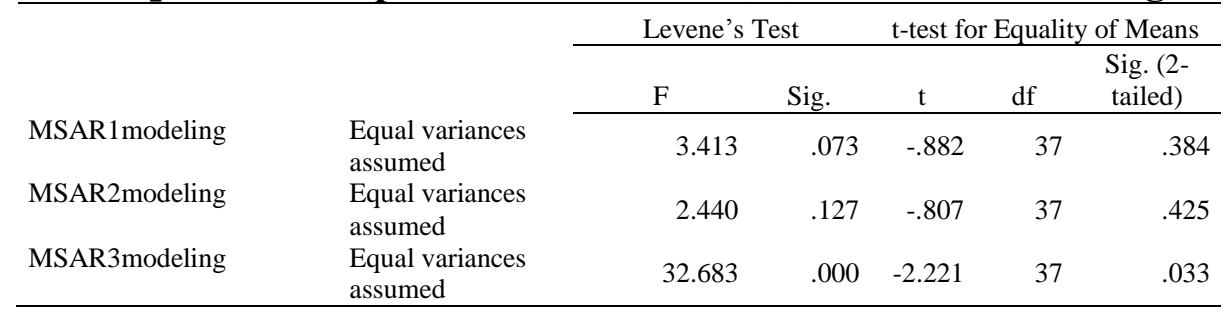

Table 5 displays the descriptive statistics of the strategy part of the 3 MSAR worksheets. Strategy refers to the solution strategy of setting up mathematical equations and such to arrive at a solution of the given problem. The mean scores of class 1 of 21 students and class 2 of 18 students(not all students turned in the worksheets) for the strategy part of the 3 worksheets show very small difference at $M=3.90$ and $M=3.89$ for worksheet $1, M=4.00$ and $M=3.89$ for worksheet 2 , and $M=3.86$ and $M=3.67$ for worksheet 3 .

Table 5

MSAR Group Statistics for "Strategy"

\begin{tabular}{|c|c|c|c|c|}
\hline \multicolumn{5}{|c|}{ Group Statistics } \\
\hline & Group\# & $\mathrm{N}$ & Mean & Std. Deviation \\
\hline \multirow{2}{*}{ MSAR1strategy MSAR 1-strategy } & 1 Class 1 & 21 & 3.90 & .301 \\
\hline & 2 Class 2 & 18 & 3.89 & .471 \\
\hline \multirow[t]{2}{*}{ MSAR2strategy MSAR 2-strategy } & 1 Class 1 & 21 & 4.00 & .000 \\
\hline & 2 Class 2 & 18 & 3.89 & .323 \\
\hline \multirow[t]{2}{*}{ MSAR3strategy MSAR 3-strategy } & 1 Class 1 & 21 & 3.86 & .478 \\
\hline & 2 Class 2 & 18 & 3.67 & .686 \\
\hline
\end{tabular}

Table 6 displays the results of the t-test. This is comparing the worksheet scores of the strategy part of all 3 worksheets for the two groups being studied, class 1 and class 2 . Worksheet 1 was on circles. Table 6 shows there is no significant difference in mean scores between two groups $(t(37)=.127, p=.899)$

Worksheet 2 was on parabolas, also the first section of the conics unit Table 6 shows there is no significant difference in mean scores between two groups $(t(37)=1.578, p=.123$.) 
Worksheet 3 was on ellipses, the second section of the conics unit Table 6 shows there is no significant difference in mean scores between two groups $(t(37)=1.017, p=.316$.)

\section{Table 6}

Independent samples test for MSAR 1, 2, and 3 for "Strategy"

\begin{tabular}{llccccc}
\hline & & \multicolumn{3}{c}{ Levene's Test } & \multicolumn{3}{c}{ t-test for Equality of Means } \\
\cline { 2 - 7 } & & $\mathrm{F}$ & Sig. & $\mathrm{T}$ & $\mathrm{df}$ & $\begin{array}{c}\text { Sig. (2- } \\
\text { tailed) }\end{array}$ \\
\hline $\begin{array}{l}\text { MSAR1 } \\
\text { strategy }\end{array}$ & $\begin{array}{l}\text { Equal variances } \\
\text { assumed }\end{array}$ & .121 & .730 & .127 & 37 & .899 \\
$\begin{array}{l}\text { MSAR 2 } \\
\text { strategy }\end{array}$ & $\begin{array}{l}\text { Equal variances } \\
\text { assumed }\end{array}$ & 13.011 & .001 & 1.578 & 37 & .123 \\
MSAR3strategy & $\begin{array}{l}\text { Equal variances } \\
\text { assumed }\end{array}$ & 3.831 & .058 & 1.017 & 37 & .316 \\
\hline
\end{tabular}

Table 7 displays the descriptive group statistics of the reasoning part of the 3 MSAR worksheets. Reasoning refers to the explanation of the visual model, the solution strategy, and the interpretation of the answer of the given problem. The mean scores of class 1 of 21 students and class 2 of 18 students (not all students turned in the worksheets) for the reasoning part of the 3 worksheets show a difference at $M=3.8, S D=.401$ and $M=3.61, S D=.61$ for worksheet $1, M=4.00, \mathrm{SD}=0$ and $M=3.89, S D=.32$ for worksheet 2, and class 1 of 22 students with $M=3.45, S D=.51$ and class 2 of 18 students with $M=3.39, S D=.78$ for worksheet 3 .

Table 7

MSAR Group Statistics for "Reasoning"

\begin{tabular}{|c|c|c|c|c|}
\hline \multicolumn{5}{|c|}{ Group Statistics } \\
\hline & Group\# & $\mathrm{N}$ & Mean & Std. Deviation \\
\hline \multirow{2}{*}{$\begin{array}{l}\text { MSAR1 reasoning msar 1- } \\
\text { reasoning }\end{array}$} & 1 Class 1 & 21 & 3.81 & .402 \\
\hline & 2 Class 2 & 18 & 3.61 & .608 \\
\hline \multirow{2}{*}{$\begin{array}{l}\text { MSAR2 reasoning msar 2- } \\
\text { reasoning }\end{array}$} & 1 Class 1 & 21 & 4.00 & .000 \\
\hline & 2 Class 2 & 18 & 3.89 & .323 \\
\hline \multirow{2}{*}{$\begin{array}{l}\text { MSAR3 reasoning msar 3- } \\
\text { reasoning }\end{array}$} & 1 Class 1 & 22 & 3.45 & .510 \\
\hline & 2 Class 2 & 18 & 3.39 & .778 \\
\hline
\end{tabular}

Table 8 displays the results of the t-test for reasoning of MSAR 1,2, and 3. This is comparing the worksheet scores of the extent to which students explained and justified their visual model and solution strategy/answer in writing.

Worksheet 1 was on circles. Table 8 shows there is no significant difference in mean scores between two groups $(t(37)=.020, p=.231)$ 
Worksheet 2 was on parabolas, also the first section of the conics unit. Table 8 shows there is no significant difference in mean scores between two groups $(t(37)=1.578, p=.123)$

Worksheet 3 was on ellipses, the second section of the conics unit Table 8 shows there is no significant difference in mean scores between two groups $(t(38)=.321, p=.750)$

Table 8

Independent samples t-test for MSAR 1, 2, and 3 for "reasoning"

\begin{tabular}{|c|c|c|c|c|c|c|}
\hline & & \multicolumn{2}{|c|}{$\underline{\text { Levene's Test }}$} & \multicolumn{2}{|c|}{$\begin{array}{l}\text {-test for Equality } \\
\text { of Means }\end{array}$} & \multirow[b]{2}{*}{ Sig. } \\
\hline & & $\mathrm{F}$ & Sig. & $\mathrm{t}$ & $\mathrm{df}$ & \\
\hline MSAR1reasoning & $\begin{array}{l}\text { Equal } \\
\text { variances } \\
\text { assumed }\end{array}$ & 5.910 & .020 & 1.218 & 37 & .231 \\
\hline $\begin{array}{l}\text { MSAR2 } \\
\text { reasoning }\end{array}$ & $\begin{array}{l}\text { Equal } \\
\text { variances } \\
\text { assumed }\end{array}$ & 13.011 & .001 & 1.578 & 37 & .123 \\
\hline $\begin{array}{l}\text { MSAR3 } \\
\text { reasoning }\end{array}$ & $\begin{array}{l}\text { Equal } \\
\text { variances } \\
\text { assumed }\end{array}$ & 1.388 & .246 & .321 & 38 & .750 \\
\hline
\end{tabular}

\section{Summary of Major Findings}

The results of the analysis for the pre-test and post-test between the two groups shows a significant difference between the results of the two groups with the flipped learning group scoring higher overall on the post-test. This is remarkable given that the control group was at a higher level of skills to begin with and they generally do homework more consistently. This result is encouraging for the use of the flipped approach.

The analysis results of the first part of the chapter 9 test show significance between the 2 groups. Although better results were expected for the control group since they were at a higher skills level and they did more homework which meant they would remember formulas and rules more than the flipped group. Since the first part of the test was geared more toward application of the rules and formulas, it stands to reason that doing more homework will produce better results. But, again the flipped group performed better overall proving that in-class learning combined with homework is more effective than traditional learning.

The analysis results for the performance task were in favor of the flipped learning again. The performance task required remembering and integrating prior knowledge into solving the problem. Higher scores for the flipped learning group were expected since students had more practice in problem solving and were more willing to try. The expectation was met; students who were considered at a "higher level" in the control group tried only what they knew was correct and did not even try to approach the parts 
they were not sure of. Most students in the flipped group tried all sections of the task. Many of them did all parts correctly although they were not graded for correct responses, but were graded only for trying and explaining mathematically. The results of the performance task as part of the test were a way of monitoring the effects of flipped learning on independent problem solving since most of the problem solving was done within groups and with teacher support. The results were extremely satisfactory.

The analysis for the MSAR worksheets shows different results from the test results. The control group did slightly better than the flipped group. One of the reasons could be that the student population of the control group generally does better on completing assignments than the flipped class students. Since homework and classwork grades were not as consequential to the grade as test grades many students of the flipped class chose not to spend very much time on elaborating and explaining and were satisfied with the minimum credit. It is significant to mention that those students would have most likely chosen not to even try prior to the flipped treatment.

While the performance task was independent work and part of a test, the MSAR worksheets were given in class and students had the option of collaboration. The results of the performance task show clearly the advantage of the flipped over the traditional teaching. For the traditional class, no student was able to do all parts correctly, and most students completely skipped one or more parts of the problem.

\section{Discussion}

The idea for this action research on the flipped classroom is directly related to the need of an effective method of teaching mathematics for understanding. Existing literature on flipped learning or the flipped classroom showed potential for this teaching pedagogy in accomplishing this goal. Since there was not enough research done at the high school level, it was necessary to find ways to implement this flipped classroom using ideas from research done at the college level in combination with existing literature on cognition and the way students learn. According to Lave and Wagner (1990, 1991) situated cognition is the learning that happens in context and culture. The goal is to extend this acquired knowledge from skills learned for future problem solving (Szymanski \& Morrell, 2009). The idea of learning with peer support and teacher support as a more effective process for application and retention of skills and concepts leads to the necessity of devoting classroom time for problem solving. Since classroom time is limited, a compromise has to be reached to strike a good balance between problem solving sessions and lectures. The flipped classroom seems to be one way to create this balance without compromising the quality of student learning; but with the lack of existing literature on flipping the high school mathematics class, the need for this action research was evident. What applies to college 
students learning mathematics might not be suitable for high school students. High school students have more demands on their time with packed academic and extra-curricular activities, and they do not enjoy the flexibility that college students might have in scheduling their classes. More importantly, high school students might not have developed enough skills as college students to learn independently from online lectures.

Although the results of the data analysis did not show significant difference in test scores in every case between the flipped and traditional classrooms, the flipped classroom was of benefit for the group of students who practiced it. Students of the flipped classroom were exposed to learning in a supportive group environment with rigorous and complex problem solving sessions. Often, there were whole class discussions as a direct result of the group sessions which constitute active learning. Active learning increases student engagement (Freeman et al., 2014) and when students are engaged they stand a better chance of understanding and retaining. Performance task scores of both tests show a significant difference in favor of the flipped method over the traditional method. Teachers might find that change from repeatedly modeling examples for students is necessary if students are to learn to be independent problem solvers. The question remains as to how each teacher will accomplish this task. Specifically, the result of the performance task is evidence that students who would have not even attempted the task, not only attempted it, but most students arrived at logical and viable answers. The performance task was given on a test without peer support; this is what makes it significant. All the work done in groups leading up to the test produced the desired effect. This finding could impact the future of teaching mathematics in a high school classroom.

\section{Recommendations and Conclusions}

In this study, all students had been asked to do the MSAR worksheets on Chapter 9 Conic Sections concepts of circle, parabola, and ellipse several times throughout the school year leading up to that point. Therefore, all students had equal time to work on MSAR worksheets and they all understood what was expected of them. Although the analysis was slightly in favor of the traditional classroom in case of the MSAR results, in reality- the flipped learning students were the ones who traditionally would not have tried doing the MSAR type problems before the flipped treatment. The control group students are the ones who went beyond the required standard to complete assignments to the best of their ability. Since all students were consistently required to show and explain all work for the months preceding the assessments, all students came through and showed improvement in discussing and showing work. Students needed the constant exposure to real world application problems in order to become comfortable with them. They also needed to work in a safe environment where they could ask questions, 
make mistakes, and get answers knowing that making mistakes is part of the learning process (Furner \& Gonzalez, 2011).

This study was conducted over one semester although preparations for it started the previous semester. The teacher/researcher set the plan in motion by starting the flipped learning very slowly for the first semester. Students needed time to adjust to the change in the learning and teaching style. For most students, the change was a relief from having to do difficult mathematics as homework, but for a few students, it was still a difficult transition and they were not willing to accept the change. Fewer students still considered this method as the teacher "not teaching" since they were not watching endless examples worked out for them to emulate while doing homework. The flip was modified by offering short lectures and a few examples to model basic skills since high school students might not be ready to learn a new concept independently. At home, students were asked to work for an average of one hour on a particular assignment including note-taking and problem solving. By doing so, the idea was they will have well thought out questions whichwhen answered in class- will help clarify concepts for each individual as needed. The questions might be answered by teacher or peers depending on the complexity and depth of the required explanation.

This study has many implications for future teaching. Since it was in the experimentation stages for the first school- year, two tests and 3 MSAR's were analyzed. Further study is needed to measure the effect of the flip over a whole school-year. Focus could be more on doing class work and less assigned homework. This could prove beneficial for younger students who need more teacher input. To avoid misinterpretation, class work needs to be in the form of complex and rigorous problems or projects and not practice of exercises and simple skills applications. The simple skills applications must be part of what students do at home to save class time for the more difficult problem solving and concept explorations. Student mathematical strengths and weaknesses are assessed the first few weeks of school through class work and teacher monitoring. Students are introduced to the rigor and complexity expected of them through class work which helps create a safe work environment rather than create anxiety with difficult homework exercises. A slow and easy transition to the flip must be almost seamless so as to reduce student resistance to the change in the status quo of years of learning in the traditional classroom. The next question to be answered would be: how effective is the flip in promoting accuracy in solving problems and mathematical reasoning?

The results of the study were favorable. Student engagement and understanding increased more with the flipped classroom over the traditional classroom. The results are encouraging and carry implications for further implementation of the flip as a success in the high school mathematics classroom. Caution is warranted since the study was done with a small number of precalculus students who were designated as honors students. The 
results may not be generalized for high school students in lower grades or of average to lower than average mathematical abilities. If the flip is to be implemented with a different grade level and/or different mathematical abilities, adjustments and changes in the implementation process must be considered. The flip in some form might still be an option with any level class given the potential benefit for increase in student mathematical understanding and participation in problem solving. Also the MSARs were not graded on accuracy to encourage students to participate in showing and explaining their work. For future studies, grading for accuracy in the second semester when students have had enough practice in showing work could be a goal.

This study is significant to high school teachers who are considering the Flipped Classroom as a teaching model. There are not enough studies conducted on flipping the mathematics classroom at the high school level. Research done on college math classes might not be applicable to high school students for at least two reasons. The first: mathematics students in college have made the choice to be in those classes, and therefore are motivated to succeed. High school students are still at an exploratory stage in their math education. They may or may not choose a college path which requires advanced math skills. The second: most college students are mature enough to take the responsibility for their own learning and would most likely do the online assignments and be prepared for the classroom discussions, while very few high school students would accept the responsibility of learning any concepts at home without initial teacher input. This study is also significant for this teacher/researcher, since it is an investigation of the possible benefits of flipping the classroom for the Precalculus students who were the subject of the study and how to apply it to future classes. The teacher's job is to prepare Precalculus students for the rigor and complexity of an Advanced Placement Calculus course. Most Algebra teachers focus on simpler procedures and skills and do not train students in complex problem solving, may be due to time restrictions. If the time restriction is the reason teachers do not engage students in enriching problem solving sessions, then the Flipped Learning model could be an answer. As students become confident in their ability to solve math problems with reasoning, they are more likely to choose a math related field of study. There is a national need for students who choose a STEM field of study identified by several educational, business, and government entities. Therefore, this research is significant in influencing future policy decisions in the form of financial support for technology and teacher training.

It was evident that students had to accept the change in the teachinglearning style for the method to be effective. Administrators and parents need to be educated on the flipped classroom through research and literature which may result in support for the teachers willing to implement it. In a Doctoral dissertation on flipped learning Overmyer stated that Byron high school in Minnesota reported increased scores in mathematics for students after 
implementing the flip and students reported a preference for the flip over the traditional learning method (Overmyer, 2014). This study shows that students who were just above average in study skills were more willing to go along with this learning approach than students who had excellent study skills. Students who completed all homework ahead felt they did not need the problem solving session; instead they wanted the teacher to give them a quick answer to their question just the way they have been learning mathematics all along. All students can benefit from flipped learning as the results of the performance task show, and it is important to find ways to convince them to try. Forcing students into a particular method of learning might not be productive.

This research showed that the flipped classroom is a viable pedagogical option to use at the high school level. Students who are confident in their math abilities are more likely to major in STEM fields of study. Therefore, it is necessary to conduct more research to further determine how the flipped learning might be implemented for different levels of high school math students.

\section{References}

An, S., \& Wu, Z. (2014). Using the evidence-based MSA approach to enhance teacher knowledge in student mathematics learning and assessment. Journal of Mathematics Education, 7(2), 108-129.

Bergmann, J., \& Sams, A. (2012). Flip your classroom: reach every student in every class every day. International Society for Technology in Education. Eugene, Or. : Alexandria, VA.: International Society for Technology in Education

Bishop, J. L., \& Verleger, M. A. (2013, June). The flipped classroom: a survey of the research. In ASEE National Conference Proceedings, Atlanta, GA.

Common Core State Standards Initiative. (2010). Common core state standards for mathematics. Washington, DC: National Governors Association Center for Best Practices and the Council of Chief State School Officers.

Van Roekel, N. P. D. (2008). Technology in schools: the ongoing challenge of access, adequacy and equity. National Education Association, Washington $D C$.

Freeman, S., Eddy, S. L., McDonough, M., Smith, M. K., Okoroafor, N., Jordt, H., \& Wenderoth, M. P. (2014). Active learning increases student performance in science, engineering, and mathematics. Proceedings of the National Academy of Sciences, 201319030 
Furner, J. M., \& Gonzalez-DeHass, A. (2011). How do students' mastery and performance goals relate to math anxiety. Eurasia Journal of Mathematics, Science \& Technology Education, 7(4), 227-242.

Hamdan, N., McKnight, P., McKnight, K., \& Arfstrom, K. (2013). The flipped learning model: a white paper based on the literature review titled a review of flipped learning. Arlington, VA: Flipped Learning Network.

Honeycutt, B., \& Garrett, J. (2014). Expanding the definition of a flipped learning environment. Faculty Focus. Magna publications

Moore, A. J., Gillett, M. R., \& Steele, M. D. (2014). Fostering student engagement with the flip. Mathematics Teacher, 107(6), 420-425.

Overmyer, G. R. (2014). The flipped classroom model for college algebra: Effects on student achievement (Doctoral dissertation, Colorado State University).

Schwerdt, G., \& Wupperman, A.C. (2011). Is traditional teaching really all that bad? A within-student between- subject approach. Economics of Education Review, 30(2), 365-379.

Smarter Balanced Assessment Consortium. (2012). Smarter balanced assessments. Retrieved from: http://www.smarterbalanced.org/

Szymanski, M. \& Morrell, P. (2009). Situated cognition and technology. The International Journal of Learning, 15(12) 55-56.

Talbert, R. (2014). Inverting the linear algebra classroom. Primus, 24(5), 361374. DOI: $10.1080 / 10511970.2014 .883457$

Watkins, J., \& Mazur, E. (2013). Retaining students in science, technology, engineering, and mathematics (STEM) majors. Journal of College Science Teaching, 42(5), 36-41.

Yarbro, j., Arfstrom, K., McKnight, K., \& McKnight, P. (June, 2014). Extension of a review of flipped learning. Retrieved from http:/www.flippedlearning.org/cms/lib07/VA01923112/Centricity/Do main/41/Extension\%20of\%20FLipped\%20Learning\%20LIt\%20Revie w\%20June\%202014.pdf.

\section{Author:}

Dunia Zeineddine

Long Beach Unified School District, California

Email: Dunia.zeineddine@gmail.com 
Rubric for MSAR worksheets:

\begin{tabular}{|l|l|l|l|}
\hline Level & \multicolumn{1}{|c|}{ Modeling } & \multicolumn{1}{|c|}{ Strategies of Computation } & \multicolumn{1}{c|}{ Reasoning } \\
\hline Level 4 & $\begin{array}{l}\text { Model used highly efficient and } \\
\text { meaningful, revealing } \\
\text { comprehensive understanding }\end{array}$ & $\begin{array}{l}\text { No computational errors and } \\
\text { used a flexible or creative } \\
\text { strategy in computation, } \\
\text { revealing complete } \\
\text { understanding of solving }\end{array}$ & $\begin{array}{l}\text { The process of MSA } \\
\text { explained with } \\
\text { academic language and } \\
\text { deep understanding. }\end{array}$ \\
\hline Level 3 & $\begin{array}{l}\text { Appropriate model used, and the } \\
\text { process of modeling } \\
\text { demonstrated }\end{array}$ & $\begin{array}{l}\text { No computational errors, but } \\
\text { solved problem by routine way } \\
\text { or only by trial and error }\end{array}$ & $\begin{array}{l}\text { Appropriate } \\
\text { explanation. }\end{array}$ \\
\hline Level 2 & $\begin{array}{l}\text { Appropriate model used, but } \\
\text { either not fully demonstrated, or } \\
\text { possibly based the operation } \\
\text { only, did not show the process of } \\
\text { conceptual developing }\end{array}$ & $\begin{array}{l}\text { Only few computational errors, } \\
\text { but followed rules and formulas } \\
\text { on computations (routine way), } \\
\text { or only by trial and error }\end{array}$ & Incomplete reasoning. \\
\hline Level 1 & $\begin{array}{l}\text { Either no model or model } \\
\text { completely inappropriate }\end{array}$ & $\begin{array}{l}\text { Either missing computation or } \\
\text { many computational errors }\end{array}$ & $\begin{array}{l}\text { Nothing or } \\
\text { inappropriate. }\end{array}$ \\
\hline
\end{tabular}

MSAR Rubric (Wu \& An 2016)

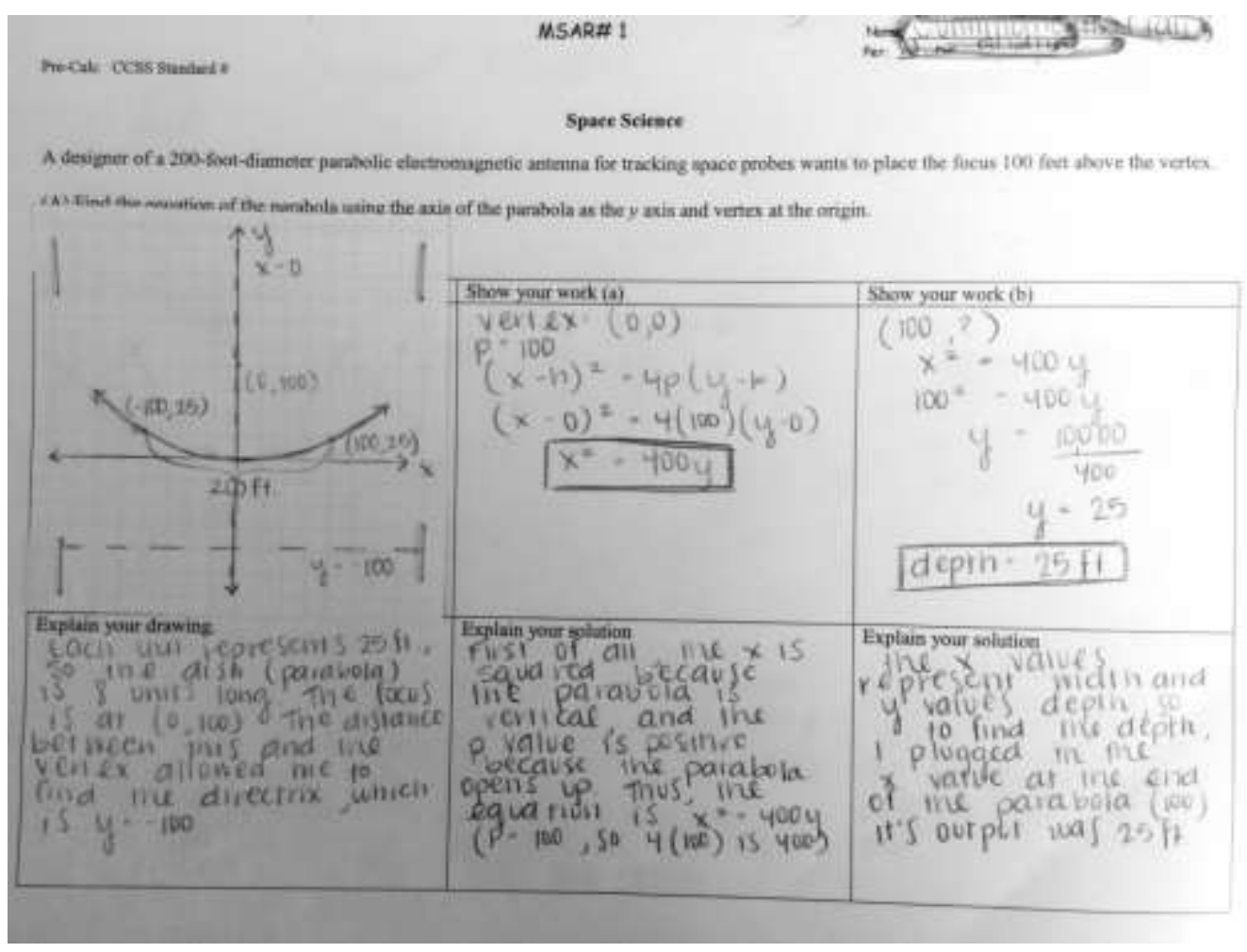

MSAR 1-student work sample \# 1 